\title{
Racial Disparities in Outcomes of Adults Hospitalized for Viral Pneumonia
}

Pius E. Ojemolon ${ }^{1}$, Valeria P. Trelles-Garcia ${ }^{2}$, Daniela Trelles-Garcia ${ }^{3}$, Asim Kichloo ${ }^{4}$, Sairam Raghavan ${ }^{2}$ , Abdulrahman I. Abusalim ${ }^{2}$, Precious Eseaton ${ }^{5}$

1. Anatomical Sciences, St. George's University, St. George's, GRD 2. Internal Medicine, John H. Stroger, Jr. Hospital of Cook County, Chicago, USA 3. Internal Medicine, Saint Francis Hospital, Evanston, USA 4. Internal Medicine, Central Michigan University, Saginaw, USA 5. College of Medicine, University of Benin, Benin City, NGA

Corresponding author: Pius E. Ojemolon, piusojemolon@yahoo.com

\section{Abstract \\ Background}

Viral pneumonia is an important cause of respiratory morbidity and mortality. Cases of viral pneumonia are becoming increasingly more common as at-risk populations increase globally. We sought to highlight the racial distribution of hospitalized patients with viral pneumonia and compare their outcomes.

\section{Materials and methods}

Data were obtained from the Nationwide Inpatient Sample (NIS) for 2016 and 2017. The study involved adults who had a principal discharge diagnosis of viral pneumonia. The primary outcome analyzed was inpatient mortality. Secondary outcomes included the development of sepsis, septic shock, acute respiratory failure, acute respiratory distress syndrome, non-ST segment elevation myocardial infarction (NSTEMI), acute kidney failure, deep vein thrombosis, pulmonary embolism, cerebrovascular accident, need for mechanical ventilation, and use of vasopressors as well as mean length of hospitalization and mean total hospital charges.

\section{Results}

Blacks and Hispanics had lower inpatient mortality adjusted odds (aOR: 0.39, 95\% CI $=0.229-0.662$, $\mathrm{p}<0.001$ and aOR: $0.55,95 \% \mathrm{CI}=0.347-0.858, \mathrm{p}=0.009$, respectively) compared to Whites. Black and Hispanic patients were also found to have lower adjusted odds ratio of having acute respiratory failure (aOR: $0.54,95 \% \mathrm{CI}=0.471-0.614, \mathrm{p}<0.001$, and $0.66,95 \% \mathrm{CI}=0.576-0.753, \mathrm{p}<0.001$, respectively).

\section{Conclusion}

Black and Hispanic patients are at lower risk of adverse outcomes when compared to White patients with viral pneumonia.

Review began 11/21/2020 Review ended 11/28/2020 Published 12/04/2020

\section{() Copyright 2020}

Ojemolon et al. This is an open access article distributed under the terms of the Creative Commons Attribution License CC-BY 4.0., which permits unrestricted use, distribution, and reproduction in any medium, provided the original author and source are credited.
Categories: Internal Medicine, Infectious Disease, Pulmonology

Keywords: mortality, pulmonary disease, viral pneumonia, racial disparity, inpatient outcomes

\section{Introduction}

Community-acquired pneumonia (CAP) is one of the leading causes of morbidity and mortality worldwide. According to World Health Organization (WHO) estimates, 450 million cases of pneumonia are recorded globally, with approximately four million mortalities per annum. CAP is known to be particularly prevalent among children and the elderly [1]. In the United States, there were 1.3 million visits to emergency departments with pneumonia as the primary diagnosis in 2017, and the annual health care cost spent on CAP exceeds $\$ 10$ billion $[2,3]$. Of the cases of pathogen-diagnosed CAP, viruses are identified in $13-50 \%$ of cases as sole pathogens while $8-27 \%$ of cases are mixed bacteria-virus infections $[4,5]$.

The most common causes of viral pneumonia are influenza, respiratory syncytial virus (RSV), rhinoviruses, and coronaviruses. Less commonly implicated viruses include adenoviruses, parainfluenza virus, and the human metapneumovirus. Enzyme-linked immunosorbent assays (ELISA), immunofluorescence, and polymerase chain reaction (PCR) tests are the most widely used diagnostic tests in the workup of patients with viral pneumonia [6].

Over the last several decades, there has been an increase in the knowledge base and general awareness of viral pneumonia due to multiple epidemics and pandemics involving lower respiratory tract infections of viral origin. Additionally, there is a growing population at increased risk of viral pneumonia, increased prevalence of immunosuppressive states, and an increased realization of bacterial and viral co-infection necessitating a higher clinical index of suspicion and early identification of respiratory viruses [7]. The effect 
of these various factors on pneumonia and other diseases has been clearly described $[8,9]$.

Variations in the distribution and outcomes of viral pneumonia based on race and ethnic demographics have been demonstrated in the United Kingdom, Australia, and New Zealand [10-12]. A review of existing literature reveals a relative paucity of studies investigating racial distribution and variations in hospitalizations and deaths resulting from viral pneumonia in the United States. To bridge this knowledge gap, we used the two most recent releases of the Nationwide Inpatient Sample (NIS) to compare outcomes of patients with viral pneumonia by race with primary emphasis on inpatient mortality.

\section{Materials And Methods Design and data source}

This was a retrospective cohort study in the US between January 1, 2016 and December 31, 2017. The NIS, the largest database of hospital inpatient stays in the United States derived from billing data submitted by hospitals to statewide data organizations across the US, was used [13,14]. It approximates a $20 \%$ stratified sample of discharges from US community hospitals, which is weighted to obtain national estimates [15]. The International Classification of Diseases, Tenth Revision, Clinical Modification/Procedure Coding System (ICD-10-CM/PCS) was used in the coding. Diagnoses are divided into a principal diagnosis; the main ICD-10 code for the hospitalization, and secondary diagnoses which are discharge diagnoses other than the principal diagnosis.

\section{Study population}

We queried the NIS 2016 and 2017 database for patients 18 years and above who had a principal discharge diagnosis of viral pneumonia including influenza due to identified novel influenza A virus with pneumonia (J09.X1), influenza due to other identified influenza virus with pneumonia (J10.0), influenza due to unidentified influenza virus with pneumonia (J11.0), and viral pneumonia, not elsewhere classified (J12). Patients were excluded if they had viral pneumonia only as a secondary diagnosis. The NIS provides data on racial distribution of the hospitalizations: Race, uniform coding: (1) White, (2) Black, (3) Hispanic, (4) Asian or Pacific Islander, (5) Native American, (6) other. We combined groups 4, 5, and 6 into "others", forming a modified racial grouping as employed in prior NIS based publications [16-21].

\section{Outcome measures}

The primary outcome was comparing inpatient mortality among patients principally admitted for viral pneumonia by race. Secondary outcomes in this population included the odds of having a secondary discharge diagnosis of sepsis, septic shock, acute respiratory failure, acute respiratory distress syndrome, non-ST segment elevation myocardial infarction (NSTEMI), acute kidney failure, deep vein thrombosis, pulmonary embolism, cerebrovascular accident, need for mechanical ventilation, vasopressors as well as mean length of hospitalization and mean total hospital charges.

\section{Statistical analysis}

Stata ${ }^{\circledR}$ Version 16 software (StataCorp., College Station, TX, USA) was used for analysis. All analyses were conducted using the weighting samples for national estimates in adjunct with Healthcare Cost and Utilization Project regulations for using the NIS database. Co-morbidities were calculated as proportions of the cohort and the Chi-squared test was used to compare these characteristics between the racial subgroups. A univariate screen was done to confirm whether confounders affected outcomes, with variables having a pvalue less than 0.2 included in the multivariate regression analysis. Multivariate regression analysis was then done to adjust for these confounders while calculating the primary and secondary outcomes. The validated MuLBSTA Score for viral pneumonia as well as the Pneumonia Severity Index was used to identify confounders [22,23]. A p of $<0.05$ was set as the level for statistical significance.

\section{Ethical considerations}

The NIS is a retrospective database lacking individual or hospital identifiers. This study was therefore exempt from our Institutional Review Board approval.

\section{Results}

\section{Patient characteristics}

The combined NIS database for 2016 and 2017 contained over 71 million weighted hospital discharges of which 89,650 satisfied the inclusion criteria for the study. These patients were adults with a principal discharge diagnosis of viral pneumonia.

White patients accounted for over two-thirds (68.2\%) and they were significantly older (70.1 vs 58.4 and 64.2 years, $p<0.001)$ compared to Blacks and Hispanics. The patients were predominantly females and were majorly insured through Medicaid. Hispanics had the highest proportion of diabetics (44.5\% vs $27.9 \%$ and $39.5 \%)$, Blacks had the highest proportion of obesity, chronic disease, and comorbid current or history of 


\section{Cureus}

malignancy, while Whites had the most proportion of hypertension, smoking history, and history of chronic obstructive pulmonary disease. Patient and hospital characteristics are detailed in Table 1.

\begin{tabular}{|c|c|c|c|c|c|}
\hline \multirow[t]{2}{*}{ Variable } & Whites (\%) & Blacks (\%) & Hispanics (\%) & Others (\%) & p-value \\
\hline & $\mathrm{n}=61,110(68.2)$ & $n=10,225(11.4)$ & $n=8,855(9.9)$ & $\mathrm{n}=9,460(10.5)$ & \\
\hline \multicolumn{6}{|l|}{ Patient characteristics } \\
\hline Age (in years), mean & 70.1 & 58.4 & 64.2 & 67.7 & $<0.001$ \\
\hline Women & 53.9 & 60.7 & 56.4 & 54.9 & $<0.001$ \\
\hline \multicolumn{6}{|l|}{ Insurance type } \\
\hline Medicaid & 71.4 & 52.5 & 56.8 & 62.4 & \\
\hline Medicare & 63.4 & 20.1 & 18.9 & 14.0 & \\
\hline Private & 20.2 & 21.0 & 18.3 & 20.4 & \\
\hline Uninsured & 2.0 & 6.4 & 6.0 & 3.2 & \\
\hline \multicolumn{3}{|c|}{ Charlson Comorbidity Index score } & & & $<0.001$ \\
\hline 0 & 19.3 & 18.7 & 18.3 & 18.7 & \\
\hline 1 & 27.9 & 23.4 & 25.9 & 27.2 & \\
\hline 2 & 19.6 & 17.0 & 19.0 & 19.6 & \\
\hline$\geq 3$ & 33.2 & 40.9 & 36.8 & 34.5 & \\
\hline \multicolumn{3}{|c|}{ Median annual income in patient's zip code, US\$ ${ }^{\#}$} & & & $<0.001$ \\
\hline $1-43,999$ & 23.2 & 54.4 & 41.5 & 23.2 & \\
\hline $44,000-55,999$ & 26.8 & 19.6 & 25.1 & 23.5 & \\
\hline $56,000-73,999$ & 26.0 & 16.1 & 20.1 & 28.4 & \\
\hline$\geq 74,000$ & 24.0 & 9.9 & 13.3 & 24.9 & \\
\hline \multicolumn{6}{|l|}{ Co-morbidities* } \\
\hline Diabetes & 27.9 & 39.5 & 44.5 & 34.4 & $<0.001$ \\
\hline Hypertension & 42.3 & 39.7 & 39.3 & 38.9 & 0.002 \\
\hline Smoking history & 39.8 & 37.8 & 30.7 & 32.6 & $<0.001$ \\
\hline CHF & 22.9 & 23.4 & 22.3 & 22.0 & 0.706 \\
\hline CKD & 15.2 & 24.6 & 18.4 & 17.9 & $<0.001$ \\
\hline Obesity & 16.1 & 23.9 & 19.3 & 14.0 & $<0.001$ \\
\hline Chronic IHD & 25.5 & 18.4 & 21.6 & 21.1 & $<0.001$ \\
\hline Prior CVA & 2.0 & 3.0 & 2.7 & 2.1 & 0.016 \\
\hline COPD & 28.4 & 20.4 & 18.5 & 20.9 & $<0.001$ \\
\hline Dependent on $\mathrm{O}_{2}$ & 7.3 & 5.6 & 4.9 & 5.7 & $<0.001$ \\
\hline Liver disease & 2.8 & 2.6 & 4.8 & 4.0 & $<0.001$ \\
\hline Anemia & 22.3 & 32.4 & 26.3 & 26.5 & $<0.001$ \\
\hline Malignancy & 37.1 & 44.1 & 38.5 & 40.7 & $<0.001$ \\
\hline \multicolumn{6}{|c|}{ Hospital characteristics } \\
\hline Hospital region & & & & & $<0.001$ \\
\hline
\end{tabular}




\section{Cureus}

\begin{tabular}{|c|c|c|c|c|c|}
\hline Northeast & 19.4 & 19.0 & 16.5 & 15.5 & \\
\hline Midwest & 28.0 & 22.5 & 8.5 & 23.7 & \\
\hline South & 33.7 & 51.1 & 42.3 & 21.6 & \\
\hline West & 18.9 & 7.4 & 32.7 & 39.2 & \\
\hline Hospital bed size & & & & & 0.001 \\
\hline Small & 23.8 & 19.3 & 21.9 & 20.9 & \\
\hline Medium & 28.1 & 26.1 & 29.6 & 25.8 & \\
\hline Large & 48.1 & 54.6 & 48.5 & 53.3 & \\
\hline Urban location & 85.9 & 94.1 & 94.8 & 85.9 & $<0.001$ \\
\hline Teaching hospital & 60.0 & 75.7 & 69.2 & 62.3 & $<0.001$ \\
\hline
\end{tabular}

TABLE 1: Distribution of patient and hospital characteristics of viral pneumonia hospitalizations by race

\#: for 2017. *: Co-morbidities were secondary diagnoses. CHF: Congestive heart failure, CKD: Chronic kidney disease, COPD: Chronic obstructive pulmonary disease, CVA: Cerebrovascular accident, IHD: Ischemic heart disease

\section{Primary outcome: in-hospital mortality}

The in-hospital mortality for viral pneumonia was $2.22 \%$ of the total cohort. The crude mortality rate was highest among Whites (2.55\%). Both Blacks and Hispanics had lower adjusted odds ratios of inpatient mortality (aOR: 0.39, 95\% CI $0.229-0.662$, p<0.001 and aOR: 0.55, 95\% CI $0.347-0.858, \mathrm{p}=0.009$, respectively) compared to Whites. We made adjustments for both hospital and patient variables including comorbidities.

\section{Secondary outcomes}

The total length of hospitalization and the total hospital charges between the Blacks and Hispanic groups were compared to Whites using multivariate linear regression model. Blacks and Hispanics had mean decreases in length of hospitalization (-0.5, CI: $(-0.761-[-0.196], \mathrm{p}=0.001$ and $(-0.3$, CI: $(-0.597-[-0.103]$, $\mathrm{p}=0.006$, respectively) compared to Whites. There was however no difference in mean total hospital charge between them. Black and Hispanic patients were found to have lower adjusted odds ratio of having acute respiratory failure (aOR: 0.54, 95\% CI: $0.471-0.614, \mathrm{p}<0.001$, and 0.66, 95\% CI: $0.576-0.753, \mathrm{p}<0.001$ respectively). However, Blacks had higher odds of developing acute kidney failure (aOR: 1.20, 95\% CI: 1.043 - 1.386, $\mathrm{p}=0.011$ ) when compared to Whites. Detailed outcomes are provided in Tables $2,3$. 


\section{Cureus}

\begin{tabular}{|lllll|}
\hline Outcome & Whites (\%) & Blacks (\%) & Hispanics (\%) & Others (\%) \\
\hline Primary outcome & & & & $(2.2)$ \\
In-hospital mortality & $(2.6)$ & $(1.0)$ & $(1.4)$ & 5.2 \\
Secondary outcomes & & & & 55769 \\
Length of stay, mean & 5.2 & 5.2 & 5.0 & 4.9 \\
Total hospital charges, mean US\$ & 43378 & 49697 & 54922 & 1.4 \\
Sepsis & 2.9 & 2.5 & 3.6 & 2.0 \\
Septic shock & 0.9 & 1.0 & 1.0 & 4.0 \\
NSTEMI & 1.9 & 1.4 & 1.9 & 4.7 \\
Mechanically ventilated & 3.7 & 4.4 & 4.0 & 17.8 \\
Used pressors & 1.8 & 2.6 & 2.5 & 26.7 \\
Acute kidney failure & 17.1 & 20.9 & 17.3 & 1.1 \\
Acute respiratory failure & 27.2 & 17.8 & 21.0 & 1.3 \\
ARDS & 0.8 & 0.5 & 0.7 & 0.3 \\
Deep vein thrombosis & 1.2 & 1.7 & 0.9 & 0.4 \\
\hline Pulmonary embolism & 0.5 & 0.7 & 0.5 & 0.4 \\
\hline Cerebrovascular accident & 0.3 & 0.4 & & \\
\hline
\end{tabular}

TABLE 2: Clinical outcomes of hospitalizations for viral pneumonia by race

ARDS: Acute respiratory distress syndrome, NSTEMI; Non-ST segment elevation myocardial infarction 


\section{Cureus}

\begin{tabular}{|c|c|c|c|c|}
\hline \multirow[t]{2}{*}{ Outcome } & Blacks & & Hispanics & \\
\hline & $\mathrm{aOR}(95 \% \mathrm{Cl})$ & p-value ${ }^{\star}$ & aOR $(95 \% \mathrm{Cl})$ & p-value \\
\hline \multicolumn{5}{|l|}{ Primary outcome } \\
\hline In-hospital mortality & $0.39(0.229-0.662)$ & $<0.001^{\star}$ & $0.55(0.347-0.858)$ & $0.009^{\star}$ \\
\hline \multicolumn{5}{|l|}{ Secondary outcomes } \\
\hline Length of stay, mean & $-0.5^{\#}(-0.761-[-0.196])$ & $0.001^{\star}$ & $-0.3^{\#}(-0.597-[-0.103])$ & $0.006^{\star}$ \\
\hline Total hospital charges, mean US\$ & $-1736^{\#}(-6452-2981)$ & 0.471 & $4377^{\#}(-542-9297)$ & 0.081 \\
\hline Sepsis & $0.60(0.423-0.837)$ & $0.003^{*}$ & $1.04(0.783-1.382)$ & 0.784 \\
\hline Septic shock & $0.68(0.377-1.224)$ & 0.198 & $0.80(0.453-1.403)$ & 0.433 \\
\hline NSTEMI & $0.82(0.523-1.288)$ & 0.389 & $1.07(0.723-1.595)$ & 0.724 \\
\hline Mechanically ventilated & $0.81(0.625-1.061)$ & 0.128 & $0.92(0.699-1.205)$ & 0.536 \\
\hline Used pressors & $1.07(0.739-1.554)$ & 0.715 & $1.39(0.932-2.069)$ & 0.106 \\
\hline Acute kidney failure & $1.20(1.043-1.386)$ & $0.011^{\star}$ & $0.94(0.811-1.099)$ & 0.458 \\
\hline Acute respiratory failure & $0.54(0.471-0.614)$ & $<0.001^{\star}$ & $0.66(0.576-0.753)$ & $<0.001^{\star}$ \\
\hline ARDS & $0.45(0.230-0.866)$ & $0.017^{\star}$ & $0.52(0.273-1.009)$ & 0.053 \\
\hline Deep vein thrombosis & $1.35(0.870-2.030)$ & 0.183 & $0.68(0.385-1.202)$ & 0.184 \\
\hline Pulmonary embolism & $1.14(0.598-2.202)$ & 0.679 & $0.92(0.435-1.961)$ & 0.835 \\
\hline Cerebrovascular accident & $1.52(0.600-3.861)$ & 0.378 & $1.18(0.479-2.983)$ & 0.714 \\
\hline
\end{tabular}

\section{TABLE 3: Adjusted odds ratio of clinical outcomes of Blacks and Hispanics with viral pneumonia}

compared to Whites

*; statistically significant, \#; adjusted mean difference, aOR: adjusted odds ratio, Cl: confidence interval, ARDS: Acute respiratory distress syndrome, NSTEMI; Non-ST segment elevation myocardial infarction

\section{Discussion}

The crude mortality rate of the total population for viral pneumonia according to our study was $2.22 \%$. This rate was highest among Whites (2.55\%), while Blacks and Hispanics comparatively had statistically significant lower odds of inpatient mortality after adjustment for possible confounders. We also found that Blacks and Hispanics had significantly shorter lengths of hospital stay and decreased odds of acute respiratory failure, a known complication of viral pneumonia [24]. There was however no significant difference in total hospital charges accrued between the three cohorts.

The rather surprising findings of our study are contradicted by the results of a study conducted by Hausmann et al. which revealed that mortality rate associated with CAP for patients at hospitals with the majority racial composition of those attended by average African Americans $(\mathrm{OR}=1.21 ; 95 \% \mathrm{CI}=1.18-1.25)$ or Hispanics $(\mathrm{OR}=1.18 ; 95 \% \mathrm{CI}=1.14-1.23)$ was higher than for patients at hospitals with the majority racial composition of those attended by average Whites [25]. A systematic review conducted by Pan et al. in the UK buttressed this variance and showed that Blacks, Asians, and other minority ethnic groups were at increased risk of acquiring severe acute respiratory syndrome coronavirus 2 (SARS-CoV-2) and poorer clinical outcomes from the disease [26]. However, these studies analyzed all patients with pneumonia even though there are known differences in management and outcomes of bacterial pneumonia as against viral pneumonia. The prognosis of viral pneumonia has been shown to be worse in older adults, those with a history of smoking, and patients with chronic obstructive pulmonary disease (COPD) [26,27]. These factors were more prevalent among Whites in our study group. To further elucidate possible explanations for these outcomes, we recommend more large-scale studies into racial distributions and variations in outcomes of patients with viral pneumonia.

Our study has several strengths. First, the data was sourced from a large nationwide dataset, to provide a large sample size that enabled us to compare mortality outcomes despite the low inpatient mortality rate associated with this cohort of patients. Second, the nature of the database allows us to provide insights into 
the comparison of baseline demographics and hospital outcomes between different racial groups to statistically significant levels.

There are some limitations to the study. NIS database studies are subject to non-randomization. NIS database deals with hospitalizations, not individual patients, so patients admitted multiple times will be counted multiple times [28]. There was no reliable way to determine if the secondary diagnoses preceded or developed during the index hospitalization [29]. Additionally, laboratory and radiologic data that could indicate underlying disease severity and inflammatory activity are not available in the NIS database [30].

\section{Conclusions}

In summary, among adults, Blacks and Hispanics are at lower risk of adverse outcomes including length of hospital stay, respiratory complications, and inpatient mortality when compared to Whites with viral pneumonia. This racial discrepancy identified warrants further randomized studies into possible unadjusted confounders to address healthcare disparities.

\section{Additional Information}

\section{Disclosures}

Human subjects: Consent was obtained by all participants in this study. Animal subjects: All authors have confirmed that this study did not involve animal subjects or tissue. Conflicts of interest: In compliance with the ICMJE uniform disclosure form, all authors declare the following: Payment/services info: All authors have declared that no financial support was received from any organization for the submitted work. Financial relationships: All authors have declared that they have no financial relationships at present or within the previous three years with any organizations that might have an interest in the submitted work. Other relationships: All authors have declared that there are no other relationships or activities that could appear to have influenced the submitted work.

\section{References}

1. World Health Organization. Pneumonia. (2019). Accessed: October 31, 2020: https://www.who.int/newsroom/fact-sheets/detail/pneumonia.

2. National Hospital Ambulatory Medical Care Survey: 2017 Emergency Department Summary Tables. (2017). Accessed: October 31, 2020: https://www.cdc.gov/nchs/data/nhamcs/web_tables/2017_ed_web_tables508.pdf.

3. Costs for Hospital Stays in the United States, 2011: Statistical Brief \#168 . (2014). Accessed: October 31, 2020: https://europepmc.org/article/nbk/nbk179289.

4. Ruuskanen O, Lahti E, Jennings LC, Murdoch DR: Viral pneumonia. Lancet. 2011, 377:1264-75. 10.1016/S0140-6736(10)61459-6

5. Johnstone J, Majumdar SR, Fox JD, Marrie TJ: Viral infection in adults hospitalized with communityacquired pneumonia: prevalence, pathogens, and presentation. Chest. 2008, 134:1141-8. 10.1378/chest.080888

6. Jennings LC, Anderson TP, Beynon KA, et al.: Incidence and characteristics of viral community-acquired pneumonia in adults. Thorax. 2008, 63:42-8. 10.1136/thx.2006.075077

7. Walter JM, Wunderink RG: Testing for respiratory viruses in adults with severe lower respiratory infection . Chest. 2018, 154:1213-1222. 10.1016/j.chest.2018.06.003

8. Shaka H, Raghavan S, Trelles-Garcia VP, Abusalim AI, Parfieniuk A, Ojemolon PE, Azubuike C: Predicting COVID-19 using retrospective data: impact of obesity on outcomes of adult patients with viral pneumonia. Cureus. 2020, 12:10291. 10.7759/cureus.10291

9. Shaka H, Edigin E, Raghavan S, Gomez TM: The obesity paradox among patients hospitalized for bacterial pneumonia: outcomes of the nationwide inpatient sample. Chest. 2020, 158:335. 10.1016/j.chest.2020.08.332

10. Nyland GA, McKenzie BC, Myles PR, et al.: Effect of ethnicity on care pathway and outcomes in patients hospitalized with influenza A(H1N1)pdm09 in the UK. Epidemiol Infect. 2015, 143:1129-1138. 10.1017/S0950268814001873

11. Kelly H, Mercer G, Cheng A: Quantifying the risk of pandemic influenza in pregnancy and indigenous people in Australia in 2009. Euro Surveill. 2009, 14:19441.

12. Chambers S, Laing R, Murdoch D, et al.: Māori have a much higher incidence of community-acquired pneumonia and pneumococcal pneumonia than non-Māori: findings from two New Zealand hospitals. N Z Med J. 2006, 119:1978.

13. Introduction to the HCUP National Inpatient Sample (NIS), 2017. (2019). Accessed: October 30, 2020: https://www.hcup-us.ahrq.gov/db/nation/nis/NIS_Introduction_2017.jsp.

14. Edigin E, Prado V, Shaka H, Salazar M: Lung involvement in systemic lupus erythematosus increases inpatient mortality: analysis of the National Inpatient Sample. Chest. 2020, 158:A1871. 10.1016/j.chest.2020.08.1623

15. HCUP Methods Series Report \# 2014-04 . (2104). https://www.hcupus.ahrq.gov/reports/methods/methods.jsp.

16. Shaka H, Gomez TM: Bronchogenic malignancies and the obesity paradox: adding weight to a growing argument using the Nationwide Inpatient Sample. Chest. 2020, 158:1470. 10.1016/j.chest.2020.08.1326

17. Shaka H, Padilla Sorto ME, Gomez TM, Edigin E, Xu J, Yap SE: 242-LB: the obesity paradox among patients hospitalized for diabetes and its complications: outcomes of the Nationwide Inpatient Sample. Diabetes. 2020, 69:242. 10.2337/db20-242-LB 
18. Ojemolon PE, Shaka H, Edigin E, et al.: Impact of diabetes mellitus on outcomes of patients with knee osteoarthritis who underwent knee arthroplasty: an analysis of the Nationwide Inpatient Sample. Cureus. 2020, 12:e8902. 10.7759/cureus.8902

19. Edigin E, Shaka H, Eseaton P, et al.: Rheumatoid arthritis is not associated with increased inpatient mortality in patients admitted for acute coronary syndrome. Cureus. 2020, 12:e9799. 10.7759/cureus.9799

20. Asemota I, Shaka H, Ehizogie E, Asotibe J, Nwachukwu P, Eseaton P, Rivera M, Pavon MR, Akuna E: TCT CONNECT-78 coexisting protein energy malnutrition is associated with increased mortality in patients admitted for transcatheter aortic valve replacement: analysis of the National Inpatient Sample. J Am Coll Cardiol. 2020, 76:34-35. 10.1016/j.jacc.2020.09.092

21. Shaka H, Raghavan S, Edigin E: Is the presence of diabetes mellitus a poor prognostic factor during hospitalizations for bacterial pneumonia? An analysis of the Nationwide Inpatient Sample. Chest. 2020, 158:A334. 10.1016/j.chest.2020.08.331

22. Guo L, Wei D, Zhang X, Wu Y, Li Q, Zhou M, Qu J: Clinical features predicting mortality risk in patients with viral pneumonia: the MuLBSTA score. Front Microbiol. 2019, 10:2752. 10.3389/fmicb.2019.02752

23. Fine MJ, Auble TE, Yealy DM, et al.: A prediction rule to identify low-risk patients with community-acquired pneumonia. N Engl J Med. 1997, 336:243-250. 10.1056/NEJM199701233360402

24. Burk M, El-Kersh K, Saad M, Wiemken T, Ramirez J, Cavallazzi R: Viral infection in community-acquired pneumonia: a systematic review and meta-analysis. Eur Respir Rev. 2016, 25:178-88. 10.1183/16000617.0076-2015

25. Hausmann LR, Ibrahim SA, Mehrotra A, Nsa W, Bratzler DW, Mor MK, Fine MJ: Racial and ethnic disparities in pneumonia treatment and mortality. Med Care. 2009, 47:1009-17. 10.1097/MLR.0b013e3181a80fdc

26. Pan D, Sze S, Minhas JS, et al.: The impact of ethnicity on clinical outcomes in COVID- 19: a systematic review. EClinicalMedicine. 2020, 23:100404. 10.1016/j.eclinm.2020.100404

27. Restrepo MI, Mortensen EM, Pugh JA, Anzueto A: COPD is associated with increased mortality in patients with community-acquired pneumonia. Eur Respir J. 2006, 28:346-51. 10.1183/09031936.06.00131905

28. Edigin E, Kaul S, Eseaton PO: Analysis of hidradenitis suppurativa hospitalizations: a report from the National Inpatient Sample database (published online ahead of print, 2020 Nov 2). J Am Acad Dermatol. 2020, S0190-9622:32904-2. 10.1016/j.jaad.2020.10.083

29. Edigin E, Ojemolon PE, Eseaton PO, Hafeez S, Emmanuel A, Iriagbonse Rotimi A, Augustine M: Systemic sclerosis is associated with increased inpatient mortality in patients admitted for atrial fibrillation: analysis of the National Inpatient Sample (published online ahead of print, 2020 Sep 16). J Clin Rheumatol. 2020, 10.1097/RHU.0000000000001543

30. Edigin E, Ojemolon PE, Eseaton PO, Hafeez S, Emmanuel A, Iriagbonse Rotimi A, Augustine M: Rheumatoid arthritis patients have better outcomes when hospitalized for ischemic stroke: analysis of the National Inpatient Sample (published online ahead of print, 2020 Sep 10). J Clin Rheumatol. 2020, 10.1097/RHU.0000000000001563 